\title{
Role of Non-Albicans Candida and Candida Albicans in Oral Squamous Cell Cancer Patients
}

\section{Mäkinen, Anna}

2018-12

Mäkinen , A , Nawaz , A , Mäkitie , A \& Meurman , J H 2018 , ' Role of Non-Albicans Candida and Candida Albicans in Oral Squamous Cell Cancer Patients ' , Journal of Oral and Maxillofacial Surgery , vol. 76 , no. 12 , pp. 2564-2571 . https://doi.org/10.1016/j.joms.2018.06.012

http://hdl.handle.net/10138/277490

https://doi.org/10.1016/j.joms.2018.06.012

publishedVersion

Downloaded from Helda, University of Helsinki institutional repository.

This is an electronic reprint of the original article.

This reprint may differ from the original in pagination and typographic detail.

Please cite the original version. 


\title{
Role of Non-Albicans Candida and Candida Albicans in Oral Squamous Cell Cancer Patients
}

\author{
Anna Mäkinen, DDS, ${ }^{*}$ Ali Nawaz, DDS, $\dagger$ \\ Antti Mäkitie, MD, $\ddagger$ and Jukka H. Meurman, DDS, MD $\delta$
}

Purpose: This study examined the prevalence of Candida species in the saliva of oral squamous cell carcinoma patients and its effect on the mortality rate.

\begin{abstract}
Materials and Methods: One hundred patients with oral cavity squamous cell carcinoma undergoing protocol treatment at Helsinki University Hospital were recruited into the study from March 2011 through 2014. For comparison, 75 age-matched controls with no current or previously treated oral cancer were recruited. Paraffin-stimulated whole saliva samples were collected and cultivated on CHROMagar Candida medium (CHROMagar, Paris, France) to establish possible Candida growth. The API ID 32C yeast identification kit (bioMérieux, Lyon, France) and Bichro-Dubli Fumouze latex agglutination test (Fumouze Diagnostics, Levallois-Perret, France) were used for further identification of different Candida species. Patients' medical records were studied for information on their health habits and general health status, as well as tumor-related data. The patients' status regarding being alive and cancer free was checked at a follow-up point in December 2017. Descriptive statistics and cross tabulation were carried out, and the $P$ value was set at .05 .

Results: Candida species were detected in $74 \%$ of the oral cancer patients' samples, with $C$. albicans being the most common species (84\%). Other species identified were C. dubliniensis (8\%), C. tropicalis (4\%), C. glabrata (3\%), C. parapsilosis (3\%), C. sake (3\%), C. krusei (1\%), and C. guilliermondii (1\%). After the follow-up period, $63 \%$ of the patients were alive and $86 \%$ of them were cancer free. Harboring Candida species in the saliva was not associated with any increase in the mortality rate.
\end{abstract}

Conclusions: $C$. albicans was common in the oral cavity of the oral squamous cell carcinoma patients. However, in this patient population, we did not observe a statistically significant effect of the yeast on the mortality rate.

(C) 2018 American Association of Oral and Maxillofacial Surgeons

J Oral Maxillofac Surg 76:2564-2571, 2018

*PhD Student, Department of Oral and Maxillofacial Diseases, University of Helsinki and Helsinki University Hospital, Helsinki, Finland.

$\dagger$ PhD Student, Department of Oral and Maxillofacial Diseases, University of Helsinki, Helsinki, Finland.

$\ddagger$ Professor, Department of Otorhinolaryngology-Head and Neck Surgery, University of Helsinki and Helsinki University Hospital, Helsinki, Finland; and Division of Ear, Nose and Throat Diseases, Department of Clinical Sciences, Intervention and Technology, Karolinska Institutet and Karolinska Hospital, Stockholm, Sweden.

$\S$ Professor, Department of Oral and Maxillofacial Diseases, University of Helsinki and Helsinki University Hospital, Helsinki, Finland.

This study was supported by the Helsinki University Research Fund (TYH2016232) and by grants from the Medical
Society of Finland and the Finnish Society of Sciences and Letters.

Conflict of Interest Disclosures: None of the authors have any relevant financial relationship(s) with a commercial interest.

Address correspondence and reprint requests to Dr Mäkinen: Department of Oral and Maxillofacial Diseases, University of Helsinki, Haartmaninkatu 8 FI-00014, Helsinki, Finland; e-mail: anna.i.makinen@helsinki.fi

Received March 262018

Accepted June 62018

(c) 2018 American Association of Oral and Maxillofacial Surgeons 0278-2391/18/30527-5

hitps://doi.org/10.1016/i.joms.2018.06.012 
Cancer of the oral cavity and lip is a malignancy that affected an estimated 300,000 persons worldwide in 2012, making it the eleventh most frequent cancer among men and thirteenth among women. ${ }^{1,2}$ Most of the oral cavity cancers originate from epithelial squamous cells. Tobacco use and alcohol use account for the development of some $65 \%$ of cases globally and are thus considered the most important risk factors for head and neck cancers. ${ }^{1,3}$ Cessation of tobacco smoking has been shown to decrease the risk of oral cavity cancers, and previous studies have shown the risk of oral cancer among ex-smokers to reach never-smoker levels between 10 to 20 years after smoking cessation., Other proposed risk factors include viral infections, particularly human papillomavirus; poor oral hygiene; marijuana smoking; and a diet high in meat and low in fruit and vegetables. ${ }^{1,6-9}$ In addition, several other microbe-related risk factors have been discussed, including chronic Porphyromonas gingivalis and Candida infections. ${ }^{10,11}$ Previous studies also have shown the development of oral carcinoma in immune-compromised patients with chronic mucocutaneous candidiasis and infrequently with autoimmune polyendocrinopathy-candidiasisectodermal dystrophy. ${ }^{12}$

The possible association between Candida species and oral neoplasm was originally reported in the 1960s. ${ }^{13}$ It has since been shown that Candida-infected leukoplakia indeed relates to a higher rate of malignancy. ${ }^{14}$ Candida infections may play a role in the development of oral epithelial dysplasia and neoplasia, and there is an association between oral epithelial dysplasia and harboring Candida species in the oral cavity. ${ }^{10}$ Moreover, virulent Candida strains are able to metabolize ethanol to carcinogenic acetaldehyde, which may have deleterious effects on the oral mucosa. ${ }^{15,16}$ Specifically, non-albicans Candida (NAC) such as C. glabrata has been shown to produce carcinogenic amounts of acetaldehyde that may lead to the development of oral cancer. ${ }^{17}$ However, it is yet to be established whether Candida infections are indeed able to cause oral cancer.

We examined salivary mycological flora, specifically NAC and Candida albicans, in oral cancer patients receiving treatment explicitly for oral cavity squamous cell carcinoma (OCSCC). The aim of this study was to assess the presence of Candida species, in particular NAC, in the saliva of oral cancer patients and to evaluate its effect on the mortality rate of the patients. The study hypothesis was that OCSCC patients harbor a high prevalence of Candida that might link to their mortality risk.

\section{Materials and Methods}

\section{PATIENTS}

One hundred patients undergoing protocol treatment for OCSCC at the Department of Oral and Maxillofacial Diseases, Helsinki University Hospital, between 2011 and 2014 were enrolled in the study. All patients signed written consent forms for participation. The exclusion criteria included cancers of the lips or oropharyngeal area, cancers other than oral squamous cell carcinoma, and the inability to give consent. The patients were clinically examined per routine treatment protocol. The patients' medical and dental hospital records were available for analysis. Basic patient- and tumor-related characteristics were gathered, such as the patients' age, gender, medications and other medical conditions, number of teeth, use of partial or complete dentures, tobacco smoking and alcohol use, size and location of the tumor, and stage of the cancer. The patients' use of alcohol was recorded as yes for current users of any amount of alcohol and as no for current nonusers of alcohol. The patients' smoking status was recorded as yes if patients were current smokers or had ceased smoking within the past 20 years and as no if patients were never smokers or had ceased smoking over 20 years ago. The patients' status regarding being alive or deceased and having cancer or not was controlled at a follow-up point at the end of December 2017. All patients had a minimum follow-up period of 3 years.

The Research Ethics Committee of the Hospital District of Helsinki and Uusimaa approved the study (ethical permit No. 525/E6/2003 and HUS/3054/ 2017), and institutional study permission was granted.

\section{CONTROLS}

Seventy-five individuals were recruited into the study as controls. They were recruited from the Ear, Nose and Throat Disease Outpatient Clinic of the Helsinki University Hospital, as well as the Helsinki Day Activities Centre for the Elderly. The inclusion criteria were age between 35 and 100 years and no previously treated or current cancer of the head and neck area. All controls signed written consent forms for participation. Data on smoking and alcohol use habits, general health status, and denture wearing were recorded in the same manner as with the oral cancer patients.

\section{SAMPLE COLLECTION AND LABORATORY ANALYSIS}

Paraffin-stimulated whole saliva samples were collected for 5 minutes and salivary flow rates (SFRs) were recorded from all patients preoperatively, as 
well as controls. One hundred microliters of undiluted sample was cultivated on CHROMagar Candida medium (CHROMagar, Paris, France) and incubated for 2 to 3 days at $37^{\circ} \mathrm{C}$. After incubation, possible yeast growth was recorded by registering the number and appearance of colonies. All green colonies were subjected to a latex agglutination test (Bichro-Dubli Fumouze; Fumouze Diagnostics, Levallois-Perret, France) to distinguish between C. albicans and C. $d u b$ liniensis. Pure cultures of the colonies were cultivated on Sabouraud medium and incubated at $37^{\circ} \mathrm{C}$ for 1 to 2 days. Further identification of the pure-cultured colonies was performed using the API ID 32C yeast identification kit (bioMérieux, Lyon, France) with visual reading of results. The isolates were stored in $20 \%$ skim milk at $-80^{\circ} \mathrm{C}$.

In addition, the patients' and controls' oral anaerobic microbial load (AML) was measured by cultivation on Brucella medium in anaerobic conditions. A dilution series up to $10^{-6}$ dilution was made of all the samples, of which $100 \mu \mathrm{L}$ was cultivated on Brucella medium and incubated in sealed anaerobic jars (gas mixture of $0.1 \% \mathrm{O}_{2}, 5 \% \mathrm{CO}_{2}, 9.9 \% \mathrm{H}_{2}$, and $85 \% \mathrm{~N}_{2}$ ) at $37^{\circ} \mathrm{C}$ for 2 to 3 days, after which the total number of colonies was recorded.

\section{STATISTICAL ANALYSIS}

The analysis of categorical data was carried out in IBM SPSS Statistics (version 25; IBM, Armonk, NY) using descriptive statistics and cross tabulation. Differences between groups were investigated with the $\chi^{2}$ test for significance (likelihood ratio) and association. A significant association was assumed when the probability value $(P)$ was $\leq .05$. The patients' pre-existing medical conditions were classified using the 2016 version of the World Health Organization International Classification of Diseases, Tenth Revision classification system. The medication used by the patients was coded using the Anatomical Therapeutic Chemical classification system, and sedative load was calculated using the sedative load model. ${ }^{18-20}$

\section{Results}

\section{PATIENTS}

The basic characteristics of the 100 patients enrolled in the study are given in Table 1 . The patients were aged between 31 and 91 years (mean age, $68.1 \pm 10.3$ years), and $45 \%$ were women. Six patients had received treatment for previous head and neck cancer. Of the patients, $45 \%$ were nonsmokers whereas $55 \%$ were current smokers. The smokers were most commonly $(71 \%)$ below the mean age of 68.1 years. Forty-seven percent of patients reported both smoking and use of alcohol, and 32\% reported never using alcohol. Twelve patients were completely edentulous, and 13 had teeth in only 1 jaw. Thirtythree patients had partial or complete dentures.

According to the medical records, 13 patients (13\%) had been diagnosed with oral lichen planus preoperatively. The most common pre-existing medical conditions were those affecting the circulatory system (56\%), followed by endocrine, nutritional, and metabolic diseases (32\%). No pre-existing medical conditions were present in 18 patients (18\%). The average number of medications used by the patients was 3.6 $( \pm 3.2)$, with 21 patients using no daily medication. Forty-five percent of patients were using 4 or more medicines on a daily basis. The average sedative load of the patients was 0.58 , and 9 patients had a sedative load of 3 or more.

Table 2 presents the most common location of the cancer, which was the tongue (31\%) and, more specifically, the border of the tongue (24\%). Other common lesion sites included the mandibular gingiva (27\%), floor of the mouth (20\%), and maxillary gingiva and palate $(10 \%)$. The cancers were most commonly stage IV (41\%), that is, the cancers were large and moderately advanced or local lymph nodes were affected. None of the patients had received preoperative radiotherapy or chemotherapy for the current cancer; however, $45 \%$ received postoperative radiotherapy and 5\% received postoperative chemotherapy during follow-up.

After a mean follow-up time of 4.6 years (minimum, 3.0 years; maximum, 6.8 years), $63 \%$ of the patients were alive and $85.7 \%$ of them were cancer free. The mean survival of the deceased patients was 22.4 months, and $70.2 \%$ had died with or of cancer. Most commonly, the deceased patients were under the mean age of 68.1 years, had been smokers, and had been diagnosed with stage IV cancer $(27 \%$ of deceased patients).

\section{SALIVA SAMPLES}

Thirty-two percent of the patients had hyposalivation (SFR $<0.7 \mathrm{~mL} /$ minute). The mean $\mathrm{SFR}$ was $1.2 \pm 0.9 \mathrm{~mL} /$ minute.

The mean AML in the samples was $67 \pm 9$ million colony-forming units $(\mathrm{CFU}) / \mathrm{mL}$ of saliva. Of the samples, 32\% had an AML below 10 million CFU/mL whereas $5 \%$ harbored a load greater than 1 billion $\mathrm{CFU} / \mathrm{mL}$.

Candida growth was present in $74 \%$ of the paraffinstimulated whole saliva samples. The mean yeast count among yeast-positive patients was 2,461 CFU/ $\mathrm{mL}$ of saliva (median, $475 \mathrm{CFU} / \mathrm{mL}$; standard deviation, 5,224 CFU/mL; minimum, $10 \mathrm{CFU} / \mathrm{mL}$ ). Candidiasis was evident in $12 \%$ of the patients (ie, yeast count $\geq 10,000 \mathrm{CFU} / \mathrm{mL}$ ). 
Table 1. BASELINE CHARACTERISTICS OF ORAL CANCER PATIENTS WITH RESPECT TO SALIVARY CANDIDA GROWTH

\begin{tabular}{|c|c|c|c|c|c|c|c|}
\hline \multirow[b]{3}{*}{ Characteristic } & \multirow[b]{3}{*}{$\mathrm{n}$} & & & \multicolumn{2}{|c|}{$\begin{array}{l}\text { Candida } \\
\text { albicans }\end{array}$} & \multirow{2}{*}{\multicolumn{2}{|c|}{ NAC }} \\
\hline & & \multicolumn{2}{|c|}{ No Growth } & \multicolumn{2}{|c|}{ Only } & & \\
\hline & & $\mathrm{n}$ & $\%$ & $\mathrm{n}$ & $\%$ & \multicolumn{2}{|r|}{$\%$} \\
\hline \multicolumn{8}{|l|}{ Gender } \\
\hline Female* & 45 & 11 & 24.4 & 25 & 55.6 & 8 & 17.8 \\
\hline Male* & 55 & 15 & 27.3 & 31 & 56.4 & 8 & 14.6 \\
\hline \multicolumn{8}{|l|}{ Age } \\
\hline$\leq 68 \mathrm{yr}$ & 53 & 17 & 32.1 & 27 & 50.9 & 9 & 17.0 \\
\hline$>68 \mathrm{yr}^{\dagger}$ & 47 & 9 & 19.2 & 29 & 61.7 & 7 & 14.9 \\
\hline \multicolumn{8}{|l|}{ Smoking } \\
\hline Yes & 55 & 14 & 25.5 & 31 & 56.4 & 10 & 28.2 \\
\hline $\mathrm{No}^{\dagger}$ & 45 & 12 & 26.7 & 25 & 55.6 & 6 & 13.3 \\
\hline \multicolumn{8}{|l|}{ Alcohol } \\
\hline Yes $^{\dagger}$ & 64 & 15 & 23.8 & 37 & 58.7 & 11 & 17.5 \\
\hline No & 32 & 9 & 28.1 & 16 & 50.0 & 5 & 15.6 \\
\hline Status unknown & 4 & 2 & 50.0 & 2 & 50.0 & 0 & \\
\hline \multicolumn{8}{|l|}{ Pre-existing medical conditions (ICD-10) } \\
\hline Yes $^{\dagger}$ & 82 & 23 & 28.1 & 44 & 53.7 & 13 & 15.9 \\
\hline No & 18 & 3 & 16.7 & 12 & 66.7 & 3 & 16.7 \\
\hline Diseases of circulatory system* & 56 & 18 & 32.1 & 30 & 53.6 & 7 & 12.5 \\
\hline Endocrine, nutritional, and metabolic diseases* & 32 & 8 & 25.0 & 18 & 56.3 & 5 & 15.6 \\
\hline Diseases of skin and subcutaneous tissue* & 19 & 6 & 31.8 & 8 & 42.1 & 4 & 21.1 \\
\hline Diseases of digestive system (not K00-K14)* & 15 & 1 & 6.7 & 11 & 73.3 & 2 & 13.3 \\
\hline Diseases of respiratory system & 13 & 2 & 15.4 & 8 & 61.5 & 3 & 23.1 \\
\hline Mental and behavioral disorders & 12 & 2 & 16.7 & 8 & 66.7 & 2 & 16.7 \\
\hline Other* & 36 & 12 & 33.3 & 19 & 52.8 & 4 & 11.1 \\
\hline Oral lichen planus diagnosed* & 13 & 5 & 38.5 & 5 & 38.5 & 2 & 15.4 \\
\hline \multicolumn{8}{|l|}{ Medications } \\
\hline No medication & 21 & 2 & 9.5 & 14 & 66.7 & 5 & 23.8 \\
\hline 1-3 medications & 34 & 12 & 35.3 & 17 & 50.0 & 4 & 11.8 \\
\hline$\geq 4$ medications & 45 & 12 & 26.7 & 25 & 55.6 & 7 & 15.6 \\
\hline \multicolumn{8}{|l|}{ Sedative load } \\
\hline $0^{*}$ & 75 & 19 & 25.3 & 42 & 56.0 & 13 & 17.3 \\
\hline $1-2$ & 16 & 5 & 31.3 & 10 & 62.5 & 1 & 6.3 \\
\hline$\geq 3^{*}$ & 9 & 22.2 & 10.5 & 4 & 44.4 & 2 & 22.2 \\
\hline
\end{tabular}

Abbreviations: ICD-10, World Health Organization International Classification of Diseases, Tenth Revision; NAC, non-albicans Candida.

* One unknown species present in group.

$\dagger$ Two unknown species present in group.

Mäkinen et al. Candida and Oral Squamous Cell Cancer. J Oral Maxillofac Surg 2018.

\section{YEAST ISOLATES}

The most common yeast species found was C. albicans (84\%) (Table 3). The NAC strains found were $C$. dubliniensis (8.0\%), C. tropicalis (4.0\%), C. glabrata (2.7\%), C. parapsilosis (2.7\%), C. sake (2.7\%), C. krusei (1.3\%), and C. guilliermondii (1.3\%). Eight patients (eleven percent) harbored more than 1 species of Candida, with 1 patient harboring 3 different Candida species. In addition, Saccharomyces cerevisiae was present in 2 of the samples. In 2 cases we were unable to reliably identify the Candida strains in question.

\section{CONTROLS}

Of the 75 controls, 43 were women (57\%) and 32 were men. The mean age of the control group was 67.8 years $( \pm 14.9$ years; minimum, 38 years; maximum, 96 years). Only 10 controls were current smokers (13\%); however, 56\% reported using alcohol at least on a monthly basis. The mean SFR among the control group subjects was $1.5 \pm 0.8 \mathrm{~mL} /$ minute. Of these, $15 \%$ met the criteria for hyposalivation ( $<0.7 \mathrm{~mL} /$ minute) .

Candida was detected in $63 \%$ of the saliva samples of the control group. C. albicans was the most 
Table 2. ORAL CANCER SITES ACCORDING TO ICD-10 CLASSIFICATION

\begin{tabular}{lr} 
Primary Tumor & n \\
\hline & \\
C02: other and unspecified parts of tongue* & 31 \\
C03: gingiva & 31 \\
C04: floor of mouth & 20 \\
C05: palate & 6 \\
C06: other and unspecified sites of oral cavity & 12
\end{tabular}

Abbreviation: ICD-10, World Health Organization International Classification of Diseases, Tenth Revision.

* Parts of tongue excluding base of tongue.

$\dagger$ Including both maxillary and mandibular gingiva.

Including cheek mucosa, vestibules of mouth, and retromolar area.

Mäkinen et al. Candida and Oral Squamous Cell Cancer. J Oral Maxillofac Surg 2018.

common yeast species found ( $60 \%$ of the yeast-positive samples). The NAC strains detected were C. dubliniensis (5.3\%), C. glabrata (5.3\%), C. parapsilosis (1.3\%), C. guilliermondii (1.3\%), and C. kefyr (1.3\%). Seven controls harbored 2 different Candida species in the saliva, and one control harbored 3 different Candida species in the saliva.

\section{CANDIDA GROWTH IN RELATION TO PATIENT CHARACTERISTICS}

As the total numbers of different NAC strains were small, the associations between the patient characteristics and yeast growth were measured among patients having no yeast growth, having only $C$. albicans present in the saliva, and having NAC with or without $C$. albicans present in the saliva (Table 4). The only statistically significant association was found between the total AML and the yeast status of the patient. For the other parameters, no statistically significant associations were found. However, when comparing the characteristics with the presence of Candida, without taking into account whether the strains were C. albicans or NAC, we found that the associations between the variables of hyposalivation, AML, and cancer stage and the presence or absence of Candida growth in saliva were indeed statistically significant (Table 4). In addition, statistical significance was evident when we compared the presence or absence of medication with the presence or absence of Candida growth $(P=.05)$.

NAC and C. albicans were more prevalent among smokers when compared with nonsmokers. This difference, as mentioned earlier, was not statistically significant. Smokers who harbored Candida had more stage IV cancer than did Candida-positive nonsmokers ( $51.2 \%$ vs $33.3 \%, P=.05)$. The most common cancer stage among Candida-positive nonsmokers was stage I (36.4\%).

All patients who were alive and had cancer at the last follow-up $(n=5)$ had yeast-positive findings (Fig 1). However, of the patients who were alive and cancer free at the last follow-up, $72 \%$ also had yeastpositive findings. Within the group of smokers who also harbored Candida $(\mathrm{n}=41), 31.7 \%$ died within the follow-up period. In the Candida-positive group of nonsmokers ( $\mathrm{n}=33$ ), $42.2 \%$ died within the follow-up period. Harboring NAC specifically did not associate with a higher mortality rate: Of the 16 NAC-positive patients, $11(68.8 \%)$ were alive at the end of the follow-up period (Fig 2).

\section{COMPARISON OF CANDIDA GROWTH BETWEEN PATIENTS AND CONTROLS}

When comparing the results of our OCSCC patients with the results of the control group, we found that the prevalence of oral Candida carriage of the age-matched controls (63\%) was not statistically significantly different $(P=.137)$. There was also no statistically significant difference in the oral yeast loads of the

Table 3. CANDIDA SPECIES ISOLATED FROM ORAL CANCER PATIENTS AND CONTROLS

\begin{tabular}{|c|c|c|c|c|}
\hline \multirow[b]{2}{*}{ Species } & \multicolumn{2}{|c|}{ Oral Cancer Patients } & \multicolumn{2}{|c|}{ Controls } \\
\hline & No. of Samples & $\%$ of Yeast Positive & No. of Samples & $\%$ of Yeast Positive \\
\hline Candida albicans & 63 & 84 & 45 & 60 \\
\hline Candida dubliniensis & 6 & 8 & 4 & 5 \\
\hline Candida tropicalis & 3 & 4 & 0 & 0 \\
\hline Candida glabrata & 2 & 3 & 4 & 5 \\
\hline Candida parapsilosis & 2 & 3 & 1 & 1 \\
\hline Candida sake & 2 & 3 & 0 & 0 \\
\hline Candida krusei & 1 & 1 & 0 & 0 \\
\hline Candida guilliermondii & 1 & 1 & 1 & 1 \\
\hline Candida kefyr & 0 & 0 & 1 & 1 \\
\hline
\end{tabular}

Mäkinen et al. Candida and Oral Squamous Cell Cancer. J Oral Maxillofac Surg 2018. 
Table 4. CANDIDA INFECTION IN RELATION TO OCSCC PATIENTS' ORAL STATUS AND TUMOR CHARACTERISTICS

\begin{tabular}{|c|c|c|c|c|c|c|c|c|c|}
\hline \multirow[b]{2}{*}{ Characteristic } & \multirow[b]{2}{*}{$\mathrm{n}$} & \multicolumn{2}{|c|}{ No Growth } & \multicolumn{2}{|c|}{$\begin{array}{c}\text { Candida } \\
\text { albicans Only }\end{array}$} & \multicolumn{2}{|c|}{ NAC } & \multicolumn{2}{|c|}{$P$ Value } \\
\hline & & $\mathrm{n}$ & $\%$ & $\mathrm{n}$ & $\%$ & $\mathrm{n}$ & $\%$ & $\begin{array}{c}\text { Significance of } \\
\text { Association Between } \\
\text { No Yeast, C. albicans, } \\
\text { and NAC }\end{array}$ & $\begin{array}{c}\text { Significance of } \\
\text { Association Between } \\
\text { Yeast and No Yeast }\end{array}$ \\
\hline No. of teeth & & & & & & & & .342 & .933 \\
\hline Edentulous & 12 & 3 & 25.0 & 9 & 75.0 & 0 & & & \\
\hline $1-32$ teeth & 88 & 23 & 26.1 & 47 & 53.4 & 16 & 18.2 & & \\
\hline Hyposalivation & & & & & & & & .129 & .036 \\
\hline Yes & 31 & 4 & 12.9 & 22 & 71.0 & 5 & 16.1 & & \\
\hline No & 69 & 22 & 31.9 & 34 & 49.3 & 11 & 15.9 & & \\
\hline Candida load & & & & & & & & .007 & \\
\hline Low load, <100 CFU/mL* & 17 & NA & & 10 & 58.8 & 5 & 29.4 & & \\
\hline Moderate load, 100-1,000 CFU/mL & 23 & NA & & 22 & 95.7 & 1 & 4.3 & & \\
\hline High load, $>1,000 \mathrm{CFU} / \mathrm{mL}$ & 32 & NA & & 22 & 68.8 & 10 & 31.3 & & \\
\hline AML & & & & & & & & .020 & .024 \\
\hline No AML detected & 6 & 5 & 83.3 & 1 & 16.7 & 0 & & & \\
\hline$<10$ million $\mathrm{CFU} / \mathrm{mL}$ & 25 & 6 & 24.0 & 15 & 60.0 & 2 & 8.0 & & \\
\hline 10 to $<100$ million $\mathrm{CFU} / \mathrm{mL}$ & 37 & 6 & 16.2 & 22 & 59.5 & 9 & 24.3 & & \\
\hline$\geq 100$ million $\mathrm{CFU} / \mathrm{mL}$ & 30 & 9 & 30.0 & 18 & 60.0 & 3 & 10.0 & & \\
\hline Tumor site & & & & & & & & .695 & .869 \\
\hline $\mathrm{CO2}$ & 31 & 9 & 29.0 & 17 & 54.8 & 5 & 16.1 & & \\
\hline $\mathrm{CO3}^{*}$ & 31 & 7 & 22.6 & 16 & 51.6 & 6 & 19.4 & & \\
\hline $\mathrm{CO4}$ & 20 & 6 & 30.0 & 12 & 60.0 & 2 & 10.0 & & \\
\hline $\mathrm{C05}$ & 6 & 2 & 33.3 & 4 & 66.7 & 0 & & & \\
\hline C06 & 12 & 2 & 16.7 & 7 & 58.3 & 3 & 25.0 & & \\
\hline Stage & & & & & & & & .439 & .050 \\
\hline I & 28 & 11 & 29.0 & 22 & 57.9 & 5 & 13.2 & & \\
\hline $\mathrm{II}^{\dagger}$ & 18 & 3 & 16.7 & 11 & 61.1 & 3 & 16.7 & & \\
\hline III & 2 & 2 & 100.0 & 0 & & 0 & & & \\
\hline $\mathrm{IV}^{\dagger}$ & 42 & 10 & 23.8 & 23 & 54.8 & 8 & 19.1 & & \\
\hline
\end{tabular}

Note: $P$ values were calculated using the likelihood ratio $\left(\chi^{2}\right)$ with $95 \%$ significance level.

Abbreviations: AML, anaerobic microbial load; CFU, colony-forming units; NA, not applicable; NAC, non-albicans Candida; OCSCC, oral cavity squamous cell carcinoma.

* Two unknown species present in group.

$\dagger$ One unknown species present in group.

Mäkinen et al. Candida and Oral Squamous Cell Cancer. J Oral Maxillofac Surg 2018 


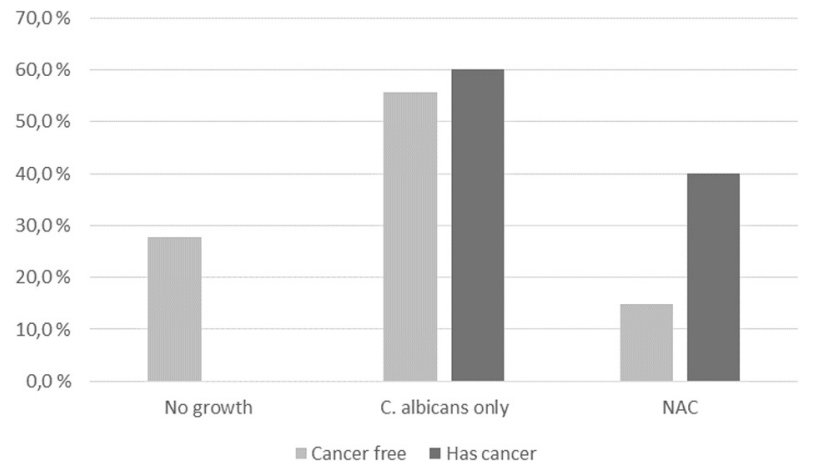

FIGURE 1. Salivary Candida status of patients who were alive at follow-up with regard to having and not having cancer. Abbreviation: NAC, non-albicans Candida.

Mäkinen et al. Candida and Oral Squamous Cell Cancer. J Oral Maxillofac Surg 2018.

OCSCC patients and the controls $(P=.245)$ : In both groups the Candida-positive individuals had mostly high salivary Candida loads (ie, >1,000 CFU/mL).

The patient group included more denture wearers (33\%) than the control group (24\%). However, 91\% of the denture-wearing patients and $83 \%$ of the denture-wearing controls were Candida positive. Both the patients and controls who reported alcohol use and/or were smokers harbored more yeast in their saliva ( $52 \%$ of patients and $39 \%$ of controls) than those who were not smokers and did not use alcohol (19\% of patients and $23 \%$ of controls).

\section{Discussion}

We investigated the presence of Candida species in the saliva of oral squamous cell cancer patients with the hypothesis that Candida species are prevalent in this patient population and would associate with the mortality rate. The results indeed showed a high presence of Candida species, with $74 \%$ of patients being

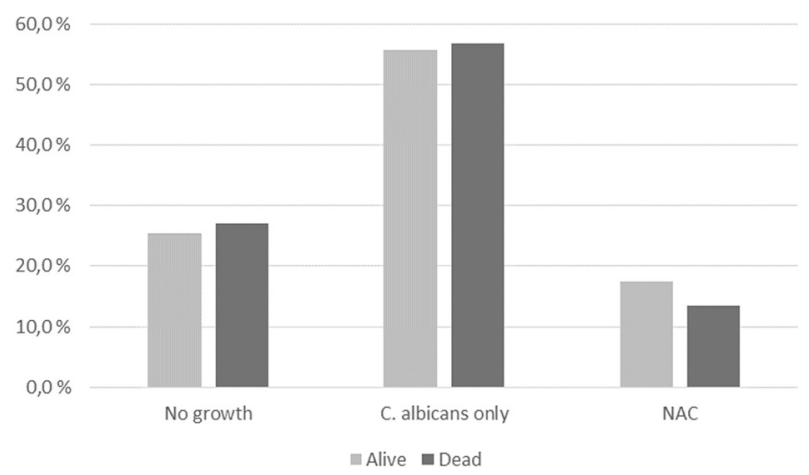

FIGURE 2. Survival status of patients (alive or deceased) at follow-up in relation to salivary Candida status. Abbreviation: NAC, non-albicans Candida.

Mäkinen et al. Candida and Oral Squamous Cell Cancer. J Oral Maxillofac Surg 2018. yeast positive and with a higher prevalence of C. albicans (84\% of yeast-positive samples) than NAC strains (23\% of yeast-positive samples). In this respect, our results are in line with previous studies. ${ }^{10,21,22}$ However, contrary to our expectation, we did not find any association between harboring Candida in the saliva preoperatively and the mortality rate.

Previous studies also have linked the presence and degree of oral epithelial dysplasia and/or neoplasia with the amount of yeast isolated in the patients' oral cavity. ${ }^{10,22}$ Our study, however, indicates that more than half (56\%) of the 72 Candida-positive OCSCC patients had yeast counts below the reference value of $1,000 \mathrm{CFU} / \mathrm{mL}$ used by McCullough et al. ${ }^{10}$ In addition, most (56\%) Candida-positive patients in our study with stage IV OCSCC $(n=32)$ had, in fact, a low level of yeast colonization $(<1,000 \mathrm{CFU} / \mathrm{mL})$. The yeast-positive patients with stage I OCSCC $(n=27)$ had varied levels of yeast carriage: $52 \%$ had a low level of yeast colonization. When we compared the mean yeast colonization levels of our study population, $68 \%$ had a lower-thanmean yeast count. It can thus be discussed that whereas the level of yeast colonization may associate with the level of oral mucosal dysplasia or neoplasia before development into carcinoma, it ceases to be a factor in the cancer growth once OCSCC is established.

As expected, the patients with a higher microbial load and lower salivary flow had more yeast growth than those with no established hyposalivation and a low AML. Saliva plays a major role in the defense of the oral cavity against harmful microbes owing to both its rinsing effect and the secretion of factors of the immunologic and other defense systems. In previous studies the sedative load has been shown to be an even more specific factor than solely the number of drugs used by a patient when one is evaluating the risk of hyposalivation. ${ }^{20}$ However, our study did not find a significant association between the sedative load or the number of drugs used and the presence of Candida in saliva. This may be because of the small overall sedative load of our patients or because the sedative load model used might not be the best means for describing factors affecting salivary flow in this age group of patients.

There was a link between the patients' cancer status at follow-up and the salivary yeast findings. This association was not statistically significant, however, and may be due to the fact that most of the patients who survived were Candida positive (55.6\%) and cancer free (85.7\%) after the follow-up period.

Our findings indicate that smokers have a higher number of NAC species when compared with nonsmokers $(28.2 \%$ vs $13.3 \%)$. This was also evident among the controls (30.0\% vs 9.5\%). Previous studies 
have shown results both for and against the effect of smoking on oral colonization of Candida. ${ }^{23,24}$ Hence, more studies are called for in this area.

Further studies also are needed with both preoperative and postoperative patient data to investigate the effect of oral Candida infections on OCSCC treatment outcome. The assessment of yeast and Candida infections preoperatively may play an important role in early diagnosis and in evaluation of the risk the yeast may pose in this patient population in general.

In conclusion, our findings showed that Candida species are prevalent in oral squamous cell cancer patients as expected. C. albicans was the predominant species, whereas NAC species were observed in lesser amounts. However, we did not observe a statistically significant effect of the yeast on the mortality rate. The results thus only partly confirmed our hypothesis, and further studies are warranted in this area.

\section{References}

1. Stewart BW, Wild CP: World Cancer Report. Lyon, France, International Agency for Research on Cancer, 2014

2. Torre LA, Bray F, Siegel RL, et al: Global cancer statistics, 2012 CA Cancer J Clin 65:87, 2015

3. Johnson N: Tobacco use and oral cancer: A global perspective. J Dent Educ 65:328, 2001

4. Blot WJ, McLaughlin JK, Winn DM, et al: Smoking and drinking in relation to oral and pharyngeal cancer. Cancer Res 48:3282, 1988

5. Varela-Lema L, Ruano-Ravina A, Juiz Crespo MA, Barros-Dios JM: Tobacco consumption and oral and pharyngeal cancer in a Spanish male population. Cancer Lett 288:28, 2010

6. Levi F, Pasche C, La Vecchia C, et al: Food groups and risk for oral and oropharyngeal cancer. Int J Cancer 77:705, 1998

7. Pavia M, Pileggi C, Nobile CG, Angelillo IF: Association between fruit and vegetable consumption and oral cancer: A metaanalysis of observational studies. Am J Clin Nutr 83:1126, 2006

8. Scully C: Oral squamous cell carcinoma; from an hypothesis about a virus, to concern about possible sexual transmission. Oral Oncol 38:227, 2002
9. Zheng TZ, Boyle P, Hu HF, et al: Dentition, oral hygiene, and risk of oral cancer: A case-control study in Beijing, People's Republic of China. Cancer Causes Control 1:235, 1990

10. McCullough M, Jaber M, Barrett AW, et al: Oral yeast carriage correlates with presence of oral epithelial dysplasia. Oral Oncol 38:391, 2002

11. Geng F, Liu J, Guo Y, et al: Persistent exposure to Porphyromonas gingivalis promotes proliferative and invasion capabilities, and tumorigenic properties of human immortalized oral epithelial cells. Front Cell Infect Microbiol 7:57, 2017

12. Firth NA, O'Grady JF, Reade PC: Oral squamous cell carcinoma in a young person with candidosis endocrinopathy syndrome: A case report. Int J Oral Maxillofac Surg 26:42, 1997

13. Cawson RA: Leukoplakia and oral cancer. Proc R Soc Med 62: 610,1969

14. Reibel J: Prognosis of oral pre-malignant lesions: Significance of clinical, histopathological, and molecular biological characteristics. Crit Rev Oral Biol Med 14:47, 2003

15. Tillonen J, Homann N, Rautio M, et al: Role of yeasts in the salivary acetaldehyde production from ethanol among risk groups for ethanol-associated oral cavity cancer. Alcohol Clin Exp Res 23:1409, 1999

16. Meurman JH, Uittamo J: Oral micro-organisms in the etiology of cancer. Acta Odontol Scand 66:321, 2008

17. Nieminen MT, Uittamo J, Salaspuro M, Rautemaa R: Acetaldehyde production from ethanol and glucose by non-Candida albicans yeasts in vitro. Oral Oncol 45:e245, 2009

18. Linjakumpu T, Hartikainen S, Klaukka T, et al: A model to classify the sedative load of drugs. Int J Geriatr Psychiatry 18:542, 2003

19. Taipale HT, Bell JS, Uusi-Kokko M, et al: Sedative load among community-dwelling people aged 75 years and older: A population-based study. Drugs Aging 28:913, 2011

20. Tiisanoja A, Syrjala AM, Komulainen K, et al: Sedative load and salivary secretion and xerostomia in community-dwelling older people. Gerodontology 33:177, 2016

21. Gallé F, Colella G, Di Onofrio V, et al: Candida spp. in oral cancer and oral precancerous lesions. New Microbiol 36:283, 2013

22. Alnuaimi AD, Wiesenfeld D, O'Brien-Simpson NM, et al: Oral Candida colonization in oral cancer patients and its relationship with traditional risk factors of oral cancer: A matched casecontrol study. Oral Oncol 51:139, 2015

23. Darwazeh AM, Al-Dwairi ZN, Al-Zwairi AA: The relationship between tobacco smoking and oral colonization with Candida species. J Contemp Dent Pract 11:017, 2010

24. Muzurovic S, Hukic M, Babajic E, Smajic R: The relationship between cigarette smoking and oral colonization with Candida species in healthy adult subjects. Med Glas (Zenica) 10:397, 2013 